\title{
Tatuajes en la memoria: autobiografía y violencia en el Perú reciente
}

Los recuerdos reviven cuando uno divisa los lugares andados porque se ven como tatuajes en la memoria. En esos lugares viví largo tiempo, y al volver sentí como si todo se bubiese detenido en algún momento, o como si fuera la nocbe larga en la Antártica o cuando el inca ató el sol, en el mito andino, para construir la ciudad imperial.

\section{Lurgio Gavilán Sánchez}

Palabras clave: subjetividad, memoria, autobiografía, violencia, Perú.

\section{Introducción}

¿Cómo se seleccionan los recuerdos y cómo funciona el olvido? ¿Todo es narrable? ¿Qué luchas políticas suceden en la construcción de una memoria reciente? ¿Cómo se organiza una narración que hilvana recuerdos? Para abordar estos cuestionamientos, se han esbozado un sinnúmero de respuestas desde diferentes prácticas narrativas y disciplinas a lo largo del tiempo. Ya sea desde la historiografía, la antropología de la memoria, la psicología cognitiva, el psicoanálisis o la escritura de las historias de vida de la etnografía, biografías o autobiografías, es posible aproximarnos a las formas en que se constituyen, en este caso, los relatos de un pasado próximo en un contexto latinoamericano de violencia: la guerra interna en el Perú durante los años 80 y 90.

A partir de la autobiografía de un campesino que, durante el devenir de su vida, cruzó las diferentes instituciones que ejercen el poder en la nación andina, nos centraremos en cómo ciertos episodios y relatos se vuelven 
significativos para el sujeto que narra y la comunidad a la que pertenece; pues, al tiempo que se construye la memoria personal, se politiza y significa también la colectiva. Este trabajo, entonces, se propone ahondar, a partir del análisis discursivo de procedimientos autobiográficos y desde un enfoque interdisciplinario, en las políticas que se disputan la conformación de una memoria reciente en el Perú.

La autobiografía de Lurgio Gavilán Sánchez -editada en 2012, prologada por Carlos Iván Degregori y comentada por Yerko Castro Neira- relata los avatares de un niño serrano quechuahablante que, siguiendo los pasos de su hermano mayor, ingresa a Sendero Luminoso (SL), donde es adoctrinado en el maoísmo y el Pensamiento Gonzalo ${ }^{1}$. Confía plenamente en los propósitos liberadores de la guerra popular convirtiéndose así en víctima y victimario, en testigo y protagonista de crímenes aberrantes. Luego, al ser cautivo por las Fuerzas Armadas (FF.AA.), y ante la protección de uno de los jerarcas que le toma simpatía, ingresa a las filas del ejército, donde también presencia y forma parte de otras vejaciones, al tiempo que se alfabetiza. Más tarde, en la orden franciscana se empapa del canon litúrgico y el bíblico, el latín y la cosmovisión cristiana. Finalmente, consciente de estos pasajes, se inscribe en la carrera de Antropología en la Universidad Nacional de San Cristóbal de Huamanga y, allí, escribe su autobiografía.

\section{Tatuajes impresos en la memoria: los textos emergentes}

La espiral de violencia en el Perú afectó principalmente a los campesinos de la zona serrana que quedaron cercados entre los fuegos de SL y las Fuerzas Armadas. Acerca de las vejaciones y secuelas se produjeron, aunque tardíamente, varios relatos que privilegiaron las formas genéricas propias de la primera persona: autobiografías, testimonios etnográficos y periodísticos. Asimismo,

1 Pensamiento Gonzalo se refiere a la propuesta política que Abimael Guzmán Reynoso (Arequipa, 1934), líder de SL, realiza cuando reinterpreta, a su criterio y sin distinción, postulados de Mariátegui y de Mao. Dice Ezcárzaga: «Guzmán advirtió la radical segmentación étnica y regional denunciada por Mariátegui, pero la reformuló a su manera, eludiendo el factor étnico, sustituyó mecánicamente los términos del conflicto costa-sierra, misti-indígena planteados por Mariátegui, por los términos maoístas ciudad-campo, y redujo el conflicto a la contradicción clasista» (2001: 14). Además, SL y Pensamiento Gonzalo se produjeron en un campo político en el que la izquierda se debatía entre una tendencia legalista, ortodoxa y pro-soviética que abogaba por un tránsito más pacífico al socialismo por la vía electoral, y otra tendencia insurreccional maoísta que proponía desarrollar una guerra popular prolongada para obtener el poder. En este marco, importa ver el papel central que jugaron los intelectuales peruanos (Ezcárzaga, 2001: 8; Stern, 1999: 37). 
emergieron otros textos literarios (sobre todo, novelas de corte policial) y otros artísticos como performances, instalaciones, historietas humorísticas, canciones, fotografías, filmes. A propósito, puede resultar interesante la lectura de Poéticas del duelo. Ensayos sobre arte, memoria y violencia política en el Perú (2015) de Víctor Vich, libro en el que se ocupa de aquellos dispositivos culturales que dan cuenta de las versiones hegemónicas y sus fisuras en la historia peruana reciente.

Por ejemplo, Chungui. Violencia y trazos de memoria (2005) del retablista y antropólogo Edilberto Jiménez se inscribe dentro del testimonio etnográfico ${ }^{2}$. Publicado por el Instituto de Estudios Peruanos (IEP) y la Comisión de Derechos Humanos (COMISEDH), narra los vejámenes sufridos en Ayacucho por medio de la imbricación del lenguaje verbal y el icónico. Así, relatos breves, que mantienen un registro descarnado sin búsquedas poéticas, completan su sentido con sencillos dibujos que el etnógrafo traza a mano alzada, mientras escucha a los informantes. Esta mixtura se inscribe, tal como lo señala el prólogo, en la tradición de La nueva coronica i Buen Gobierno (1615) de Guamán Poma de Ayala.

También incluimos aquí los brutales testimonios recopilados en Informe Final por la Comisión de la Verdad y la Reconciliación (CVyR) del 2003. Luego de un poco más de una década de lucha, estos relatos se han instalado en el campo cultural logrando así «ingresar [sus conclusiones] en el imaginario nacional» (Vich, 2009: 4). De este modo, se puede discutir las responsabilidades ciudadanas y políticas del conflicto ${ }^{3}$.

Entre los relatos periodísticos, atentos a las demandas del mercado editorial, encontramos casos como La cuarta espada. La bistoria de Abimael Guzmán y Sendero Luminoso (2007) de Santiago Roncagliolo. A modo de best sellers, esta biografía reconstruye la infancia y la formación universitaria en Arequipa del líder de SL, sus lecturas sobre el maoísmo y las excéntricas relaciones que

2 Me refiero a los textos fundacionales del género testimonial, cuyo auge se produjo en la década de los 80, como lo son Me llamo Rigoberta Menchú y así nació mi conciencia (1983) de Elizabeth Burgos Debray y Si me permiten hablar... Testimonio de Domitila, una mujer de las minas de Bolivia (1977) de Moema Viezzer. El testimonio hispanoamericano, como es sabido, se trata de un género híbrido que imbrica formas propias del discurso literario y el etnográfico. Además, aún hoy siguen vigentes las problemáticas en torno a este género: los pasajes de la oralidad a la escritura, la autoría compartida entre informante y amanuense, los procesos de canonización del género, por ejemplo.

3 Estas conclusiones son revisitadas y cuestionadas continuamente por los estudiosos en el tema. A propósito, remitirse a las apreciaciones de Carlos Iván de Gregori, referente ineludible en el estudio de la guerra interna y sus secuelas: http://books.openedition.org/ ifea/562?lang=es $(01-08-2015)$. 
establece con los planteos de Mariátegui, su liderazgo político unipersonal, sus relaciones con los militantes y sus relaciones amorosas. Para ello, Roncagliolo realiza una serie de entrevistas a diferentes actores, entre los cuales -casual o desafortunadamente- no se halla Abimael Guzmán.

«Mi secuestro» (1999) de Hory Chlimper es también un relato autobiográfico, aunque su impacto entre la crítica ha sido más bien negativo, debido al posicionamiento ideológico del empresario. Narra la experiencia de su secuestro en 1990, en Lima, por un comando del Movimiento Revolucionario Túpac Amaru que lo mantiene cautivo en un pequeño cajón de madera durante ocho meses. Desde otro lugar, se ha publicado Los Rendidos. Sobre el don de perdonar (2015), de José Carlos Agüero, que -entre el ensayo, la no-ficción y la autobiografía - relata la historia de un hijo de senderistas.

A estas escrituras del yo deben sumarse, por supuesto, las ficcionales que se escribieron posteriores al conflicto pues, durante los años de la guerra interna, como lo señalan Cornejo Polar y Vidal (1984), la literatura peruana enmudeció. Más tarde, estas producciones dan cuenta del conflicto armado y sus consecuencias en un Perú que aún permanece herido. Entre ellas, podemos mencionar a los autores criollos y andinos ${ }^{4}$ que, siguiendo una u otra tradición, y echando mano al realismo urbano o a géneros como el policial, rompen el silencio inicial. Nos referimos a las escrituras de Miguel Gutiérrez, Oswaldo Reynoso, Óscar Colchado Lucio, Mario Vargas Llosa5, Santiago Roncagliolo, Alonso Cueto, Ivan Thays, Daniel Alarcón, por nombrar sólo algunos.

En este prolífico y heteróclito campo reciente, ¿jpor qué interesarnos por la autobiografía de Lurgio Gavilán Sánchez? Quizá porque, a propósito del giro subjetivo del que nos habla Beatriz Sarlo (2005), contemporáneo al giro lingüístico, y que pone en primer plano a la subjetividad, nuestra mirada empieza a

4 Esta distinción ha sido realizada por la crítica literaria quien ha visto en la escritura literaria contemporánea a los escritores andinos como herederos de la tradición de José María Arguedas y los criollos descendientes de la de Mario Vargas Llosa.

5 Nos referimos puntualmente a Lituma en los Andes (1993), novela que concibe a los campesinos como bárbaros y, aun, antropófagos. A partir de un logrado relato policial, se reconstruye la desaparición de tres hombres en la sierra durante la época de SL. Al final del relato, se descubre que no han sido víctimas de SL como se esperaba, sino de los «supersticiosos» habitantes de la sierra que los han sacrificado a los apus. De otra parte, recordemos que el gobierno de Fernando Belaúnde encomendó al Nobel peruano de literatura la conformación de una comisión para investigar la masacre de ocho periodistas y su guía, ocurrida en enero de 1983, en manos de los campesinos de Uchuraccay (Ayacucho). Vargas Llosa emitió un informe que redunda en el salvajismo de hombres que pertenecen a un «mundo congelado en el tiempo, atrasado y tan violento». (De Gregori, en: Lurgio Gavilán, 2012: 9) 
centrarse en las historias mínimas de sujetos anónimos. En este sentido, el relato en primera persona de la vida de este «soldado desconocido» da cuenta de cómo las diversas instituciones por las que este circuló, luchan por establecer sus propias versiones del conflicto $y$, así, constituir la memoria reciente. $\mathrm{Su}$ relato permite desprendernos de las visiones maniqueas y la leyenda de los dos demonios que recorre la historia del Perú, el Cono Sur e, incluso, el continente latinoamericano.

Lurgio se constituye, simultáneamente, en víctima y victimario: causa empatías o antipatías en sus destinatarios, se erige como un sobreviviente, un héroe o un pecador arrepentido que aspira a la santidad. Además, en el relato de los recuerdos, se yuxtaponen palabras en quechua, español y latín, como si fueran tatuajes que se dibujan, imprimen y superponen en capas permaneciendo a través del tiempo. Del mismo modo, sucede con los diferentes textos artísticos y culturales que yuxtaponen posicionamientos y estéticas en la memoria reciente.

\section{El recuerdo, tiempo detenido que se mueve constantemente}

La autobiografía de Lurgio se organiza en cuatro apartados: su pasaje por SL, las FF.AA., el convento y su regreso, siendo ya un académico, a la comunidad de origen. En numerosos momentos, se realizan reflexiones en torno a la memoria y el olvido. Por ejemplo, a la metáfora de los recuerdos como «tatuajes de la memoria» que «se alimenta[n] como las pulgas o los piojos blancos que se alimentaron de mi sangre cuando clandestino caminaba» (Gavilán Sánchez, 2012: 164), pueden añadirse otras como «un viaje a través del tiempo infinito» (2012: 170) o «rocas madres resistiéndose al tiempo» (2012: 172). El retorno a su tierra natal, los lugares de su infancia y su militancia en el Partido Comunista Peruano (PCP), significan también un «regreso» al pasado a través de un relato construido desde un presente que le ayuda a sobrevivir: «estos hombres no estarían arañando estas tierras para sobrevivir como yo he arañado en mi vida para contar lo sucedido» (2012:174).

Al respecto, resulta relevante lo que Beatriz Sarlo plantea en Tiempo pasado, ensayo que se ocupa del testimonio y las subjetividades en la historia argentina reciente:

Las 'vistas de pasado' (según la fórmula de Benveniste) son construcciones. Precisamente porque el tiempo del pasado 
es ineliminable, un perseguidor que esclaviza o libera, su irrupción en el presente es comprensible en la medida en que se lo organice mediante los procedimientos de la narración $y$, por ellos, de una ideología que ponga de manifiesto un continuum significativo e interpretable de tiempo. Del pasado se habla sin suspender el presente y, muchas veces, implicando también el futuro. Se recuerda, se narra o se remite al pasado a través de un tipo de relato, de personajes, de relación entre sus acciones voluntarias e involuntarias, abiertas y secretas, definidas por objetivos o inconscientes; los personajes articulan grupos que pueden presentarse como más o menos favorables a la independencia respecto de factores externos a su dominio. Estas modalidades del discurso implican una concepción de lo social, y eventualmente también de la naturaleza. Introducen una tonalidad dominante en las 'vistas del pasado'. (2007: 13)

La intelectual argentina distingue entre las narraciones históricas de circulación masiva, en las que se reconstruyen hechos con interpretaciones de sus sentidos y se garantizan visiones globales, aunque su alcance no sea necesariamente de interés público, y aquellas de circulación masiva y modalidad no académica, que son sensibles a las estrategias con las que el presente pone en evidencia el pasado. Estas últimas se vinculan con lo testimonial y -antes que las buenas historias académicas que sostienen hipótesis- proponen certezas que ayudan al lector a sostener un sentido, una acción o un consuelo.

Al ocuparse del pasado y la memoria recientes, Sarlo concibe las formas testimoniales como aquellas que se han transformado en «ícono de la verdad» o en recurso para reconstruir el pasado. Se interesa por el uso de la primera persona como una forma privilegiada frente a discursos en los que el «yo» es desplazado o se ausenta; predilección que da cuenta de un giro subjetivo. Se trata del desplazamiento de una mirada que se preocupa por lo popular, la cotidianeidad, los sujetos «normales» que siguen los derroteros esperables y que protagonizan transgresiones e intercambios. Lejos del interés por las estructuras, se pone en relieve el sujeto, su identidad, su reafirmación a partir de la primera persona. En ese sentido, la historia de Lurgio, la de un «soldado desconocido», le permite conservar el recuerdo y reparar una identidad lastimada.

Esta identidad - no sólo la de un muchacho que ingresa a las filas de SL, sino también la de toda una nación- se halla profundamente dividida. El cuerpo nacional peruano está atravesado por un hondo conflicto que se inicia en la 
conquista misma, cuando Atahualpa en Cajamarca se «encuentra» con Pizarro y Fray Valverde. A propósito, Flores Galindo (2001) dice que la historia de violencia desencadenada con SL sólo puede entenderse en una sociedad como la peruana que, desde su conquista, se halla quebrada étnica, geográfica, social y culturalmente. $Y$ en ese quiebre se estigmatiza a un sector: el indígena que en la guerra interna queda atrapado entre dos fuegos e, incluso, se hiere a sí mismo.

Víctor Vich señala que, entre las diferentes versiones sobre el conflicto interno, están quienes sólo responsabilizan a SL, quienes avanzan sobre las culpas de las FF.AA. y la invisibilización que el Estado peruano realiza del indígena, quienes señalan los crímenes de ambos grupos sobre la comunidad civil, y los estudios más recientes que indican cómo la población civil actúo incluso contra sí misma (2015: 12-13). Los estereotipos que asocian al indígena con el ámbito de la barbarie se imprimen en el discurso de Lurgio quien justamente proviene del espacio serrano y, aun así, niega su procedencia, prefiriendo identificarse con la civilidad del intelectual. Una vez más, nos hallamos frente al ejercicio de la violencia sobre el mundo indígena:

Allí un campesino me interroga, quiere saber quién soy y por qué estoy andando así. Me pide la identificación y mi documento de identidad nacional no estaba en mi bolsillo, entonces de inmediato se me vienen a la mente los prejuicios que ocasionaron la masacre de Uchuraccay, la justicia consuetudinaria de los comuneros y su incontrolable violencia que pintó Mario Vargas Llosa. Por un instante no dije nada. Más allá aparecieron dos campesinos más. Rebusqué en la mochila apresurado y encontré un documento que me acreditaba como académico, y eso me salvó. (Gavilán Sánchez, 2012: 168)

Si observamos esta escena y recordamos que Lurgio durante su infancia sólo hablaba el quechua, podremos advertir cómo opera todavía la matriz colonial en la nación peruana; matriz que termina reforzando el consabido estereotipo del «salvaje», surcado en el relato occidental desde el mismo «descubrimiento» del continente. De ahí, la relevancia del análisis de Vargas Llosa sobre la masacre de Ucchurakay pues, con esta referencia, se evoca toda una mirada colonizadora, desde una supuesta superioridad, sobre ese cruento e incomprensible episodio.

Sin embargo, el relato autobiográfico, donde el «yo» se ficcionaliza a sí mismo (Arfuch, 2010), se halla atravesado por la contradicción cuando también 
reivindica la cultura andina: por ejemplo, la vemos en referencias y adhesiones a la escritura de José María Arguedas; en la inclusión de mitos andinos como el del zorro o atuq; en la alusión a prácticas comunitarias ancestrales; en la transcripción de huaynos; y en la inclusión de frases y canciones en quechua ${ }^{6}$. Aún más, los diferentes apartados incluyen elementos populares: letras de los himnos senderistas, los cánticos militares en contra de los terrucos, las plegarias religiosas y los fragmentos bíblicos en español y en latín.

La memoria es un campo de conflictos, dice Sarlo (2007), y así lo vemos cuando confrontamos las versiones, por un lado, de quienes mantienen los recuerdos de los crímenes y desean que estos queden abiertos jurídicamente y, por otro, de quienes proponen pasar a otra etapa cerrando los casos más monstruosos de la historia reciente. Lejos de una concepción estanca y de recuerdos no alterados, la memoria se construye desde un presente que evoca el pasado, donde luchan versiones contrapuestas. Resulta, entonces, preciso delimitar un concepto de recuerdo. Según Joël Candau, los recuerdos de la infancia son imágenes transformadas del pasado:

[...] estamos lejos de la concepción del recuerdo como una huella pura del acontecimiento pasado, huella eventualmente alterada, falsificada, perturbada por los afectos. El recuerdo se define aquí como 'una elaboración novelada del pasado, tejida por los afectos o las fantasías, cuyo valor, esencialmente subjetivo, se establece a la medida de las necesidades y los deseos presentes en el sujeto. Por lo tanto, no puede ser concebida como un testimonio fiel del pasado. (2002: 18)

Lurgio entiende el recuerdo como un «repaso», un regreso a la comunidad de origen. Quizá, desde su discurso, se trata de una memoria cuyo tiempo se detiene o de un recuerdo que desanda caminos por los que ya transitó. Sin embargo, las contradicciones que se evidencian en su soliloquio y las tradiciones superpuestas (la andina, la militar y la eclesiástica), con sus respectivas lenguas y cosmovisiones, dan cuenta de lo contrario: una memoria que se ha modificado y no se detiene, sino que se mueve constantemente.

$6 \quad$ Las locuciones en quechua hallan su traducción en glosarios, notas al pie o entre paréntesis. Este proceso de traducción puede estar dando cuenta de la jerarquización de las lenguas, esto es, la primacía del español, al mismo tiempo que se configura como un indicador de la identidad de los lectores de estos textos. Ángel Rama se preocupa por estas cuestiones en $\mathrm{La}$ ciudad letrada (1984). 


\section{Víctima, victimario, héroe, testigo}

Lurgio regresa a su comunidad de origen luego de haber transitado por diferentes espacios y asumido distintos roles. En su retorno encuentra a un viejo a quien confunde, en sus recuerdos, con su hermano muerto durante la militancia en la guerrilla. El viejo puede ser su hermano, pero también puede ser un hombre que colaboró durante la guerra popular. Sí es, en eso hay certeza, testigo de lo ocurrido: «Rikuranim [He visto]», le dice. El relato testimonial sostiene con sus certidumbres. El viejo es un otro para el yo, Lurgio. Las complejas relaciones entre el yo y el otro, entre sus miradas y posiciones en el mundo, pueden explicarse a partir de la noción de exotopía o extraposición que propone Mijaíl Bajtín. Con ella, se refiere a una situación ligada a la deficiencia: «lo que yo veo en el otro, en mí mismo, solo el otro lo puede distinguir». Todos los demás hombres son otros para mí, se encuentran fuera7. Entonces, ¿qué sucede con esto cuando hablamos de una autobiografía donde autor y personaje coinciden?

Bajtín expone tres casos típicos de la actitud del autor hacia el personaje, atendiendo a la pérdida del punto valorativo de la extraposición: el personaje se apropia del autor, el autor se posesiona de su personaje o el personaje es su propio autor. Este último puede coadyuvarnos a leer esta historia de vida pues se trata de un personaje autosuficiente y concluido, que representa su propio papel. La orientación del personaje puede resultar valiosa para el autor ya que -atendiendo a los sentidos cognitivo, ético, religioso- contribuye a su heroización. En este sentido, se suspende el valor estético, entra en juego el valor ético (expreso en manifiestos, veredictos, discursos, injurias, confesiones, por ejemplo) y sobrevienen los aconteceres cognoscitivos (tratado, artículo, lección) o religiosos (oración, culto, rito). Si el héroe vive cognoscitiva y éticamente, reúne todas las definiciones y da conclusión a un todo singular, cabe preguntarnos por cómo se construye a lo largo del texto una figura heroica de Lurgio. Por ejemplo, durante su permanencia en las líneas de SL, el relato enfatiza la obediencia y la disposición para ofrendar hasta la propia vida:

Entonces entendí que más allá de los sentimientos fraternos consanguíneos estaba primero obedecer los mandatos del

7 «De acuerdo con la actitud, el autor debe ubicarse fuera de su propia personalidad, vivirse a sí mismo en un plan diferente de aquel en el que realmente vivimos nuestra vida; sólo con esta condición puede completar su imagen para que sea una totalidad de valores extrapuestos con respecto a su propia vida; el autor debe convertirse en otro con respecto a sí mismo como persona, debe lograrse ver con ojos de otro». (Bajtín, 2008: 24) 
partido. Ir donde te manden y ofrendar tu vida en nombre del PCP, y tu nombre permanecería grabado e impreso por los siglos de los siglos en la memoria colectiva como héroe guerrillero. (Gavilán Sánchez, 2012: 73)

El pasaje por el Ejército es aún más complejo. Si bien todas las instituciones por las que atravesó Lurgio son jerárquicas -y así lo señala cuando las compara $^{8}$ - las FF.AA. son particularmente hostiles: «En verdad no había terrucos, nosotros queríamos vengarnos de ese monarca militar» (2012: 117). Llama la atención que, en este y otros pasajes, el narrador no se preocupa por marcar la heroicidad como sí sucede en los que narra su militancia en el PCP. En cambio, opta en lo discursivo por usar la primera persona propia del testigo (be visto, be oído), o emplear formas impersonales y la tercera persona para referirse a los crímenes cometidos por la institución estatal. De esta manera, no se incluye en el cometido de los vejámenes, sino que toma distancia de ellos; por ejemplo, emplea estas estrategias cuando atestigua masacres, torturas, violaciones o casos de zoofilia:

Los que venían de la base de Razuhuillca nos contaban que los soldados tenían relaciones íntimas con las llamas y burras; pues las charlis iban pocas veces porque en esas alturas hacía mucho frío (2012: 110).

Las mujeres cocinaban el rancho (la comida) para nosotros. Eran jóvenes entre 17 y 20 años. En las noches traían a las chicas a la cuadra donde dormíamos y se acostaban con los cabitos, primero pasaban los sargentos, luego los demás hasta que se cansaran [...] Trajeron a las mujeres a la cuadra, y todos abusaron de ellas [...] Como a la medianoche llevaron a las mujeres al campo donde siempre nos formábamos. Todos fuimos a presenciar su muerte. (2012: 112-113)

La alternancia entre la primera y la tercera persona gramatical da cuenta de su distanciamiento de una institución que intenta ocultar su siniestra intervención en el conflicto interno. A esto, agregamos el empleo de cursivas para los términos en quechua o los sociolectos, como también las reformulaciones o el uso de paréntesis para aclarar sentido. Ello nos sugiere que el destinatario de

8 «Para entrar y salir del altar desde donde se dirige el padre celebrante, la columna de participantes va jerarquizada. [...] En el Ejército es todo lo contrario, el más alto rango siempre se forma primero y el recluta al último, menos en las patrullas, donde los jefes van atrás». (Gavilán Sánchez, 2012: 153) 
este relato es ajeno al espacio quechua-serrano, tal como sucede con los glosarios en las literaturas regionalistas y las indigenistas.

Para el pasaje por el ámbito eclesial emplea recursos similares: alterna entre la primera y la tercera persona para referirse a las relaciones de novicios y frailes con mujeres, logrando construir el efecto de que no participa de la transgresión a las normas religiosas. ${ }^{9}$ En cuanto al papel de la institución eclesial en el conflicto armado, el narrador contrapone la idea de «perdón», propia del discurso cristiano, a las de «amenaza» y «castigo de muerte» del PCP. ${ }^{\circ}$ Del mismo modo, sucede con la sociedad peruana que se debate entre olvidar para cerrar los casos más aberrantes y seguir así adelante, y el castigo indeleble a los culpables. En este apartado, junto con una constante mención a los niños huérfanos rescatados por la Iglesia, aparece con recurrencia la mención de «reconstrucción», «paz»y «perdón», frente a una violencia asociada tanto a indios que asesinan sacerdotes durante la conquista, como a SL que mata campesinos durante el conflicto interno.

\section{A modo de conclusión}

A lo largo de este artículo que procura ahondar, a partir de una escritura del yo, en qué relatos y qué políticas batallan por la construcción de la memoria reciente, hemos abordado, en un primer momento, un panorama de los textos literarios, artísticos, etnográficos y periodísticos que emergieron a propósito de las heridas de la guerra interna. Estos textos -aunque tardíamente, pues las literaturas y las artes enmudecieron durante los años 80- dan cuenta de un prolífico y heteróclito campo reciente que abarca diferentes géneros, lenguajes, versiones de la historia y posicionamientos ideológicos. Particularmente, nos interesamos por los géneros propios de las escrituras del yo: autobiografías y testimonios que, por su carácter híbrido y su viraje a la retórica de la subjetividad, yuxtaponen a través de la poética testimonial diferentes posicionamientos ideológicos y distintas estéticas, al tiempo que superponen el español, el latín y el quechua.

9 «Cuando acudíamos a las clases del Centro Franciscano, donde todos los franciscanos de Lima nos reuníamos, monjas y monjes nos enamorábamos. $\mathrm{O}$ con los jóvenes catequistas donde venían hermosas chicas, algún hermano postulante se enamoraba, pero, luego, las lecturas de espiritualidad franciscana nos hacían olvidarlas porque nos orientaban en que ellas eran nuestras hermanas de sangre en Cristo». (2012: 137)

10 «El perdón era una constante aquí en nuestras vidas, mientras en el PCP era la amenaza y el castigo de muerte». (2012: 141) 
En segundo lugar, hemos avanzado sobre las tensiones entre los diferentes posicionamientos institucionales e ideológicos que pueden hallarse en la autobiografía de Lurgio Gavilán. Tales tensiones aparecen a través de diferentes capas que se sobreponen en el orden lingüístico y el cultural, por ejemplo, el español y el quechua, la doctrina maoísta y la eclesiástica, la cosmovisión andina y la occidental. Además, advertimos cómo se construye la subjetividad de quien testimonia: persiste en el relato una matriz colonial que devela la negación de la procedencia indígena y prefiere, en cambio, la identificación con la figura del académico. En realidad, lo que nos sugiere esta tensión es cómo en el relato también se yuxtaponen diferentes identificaciones según su vinculación con los distintos ámbitos por los que circula; identificaciones que batallan por la construcción de la memoria: algunos sostienen continuar con la acción judicial y otros desean clausurar los recuerdos y la problemática de la memoria. Estas posiciones, por supuesto, nos conducen a cuestionarnos, desde la antropología de la memoria, acerca del dinamismo del recuerdo que no se detiene y que permite regresar de otros modos a la comunidad de origen.

En tercer lugar, y a partir de un análisis minucioso de la figura del yo autobiográfico, abordamos el modo en que se construye la figura del héroe, el victimario y la víctima también se superponen en el relato. Así, oscila en el uso de la primera y la tercera personas gramaticales para identificarse o distanciarse de los crímenes de las instituciones eclesiástica y militar, o para erigirse como héroe en la lógica senderista. Asimismo, busca construir la «santidad» en la exaltación de virtudes cristianas como el «perdón». De esta manera, con su relato, avala o se aleja de las políticas que intentan disimular la intervención funesta de las FF.AA. que puede inscribirse en el terrorismo de Estado y que negó la ciudadanía de los campesinos.

En estos tiempos signados por el giro subjetivo, la autobiografía de este «soldado desconocido» da cuenta de cómo, al configurarse una compleja memoria personal que superpone diferentes lenguajes e identificaciones, se construye una memoria colectiva. Memoria que, al igual que tatuajes superpuestos en el cuerpo, se construye yuxtaponiendo recuerdos en la nación. Memoria politizada, resultado de luchas que se desencadenan para configurar el relato dominante. De allí que en el relato de Lurgio convivan las versiones del PCP, las FF.AA., la iglesia y la universidad que se encuentran batallando a través de silencios, omisiones, ambigüedades y formas testimoniales. 


\section{Bibliografía}

Agüero, J. C. (2015): Los Rendidos. Sobre el don de perdonar. Lima: IEP.

Arfuch, L. (2010): El espacio biográfico. Dilemas de la subjetividad contemporánea. Buenos Aires: FCE.

Bajtín, M. (2008): Estética de la creación verbal. Buenos Aires: Siglo XXI.

Candau, J. (2002): Antropología de la memoria. Buenos Aires: Nueva Visión.

Chlimper, H. (1999): «Mi secuestro». En: El umbral del milenio. Lima: Sidea.

Comisión de la Verdad y la Reconciliación (28/8/2003): Informe final. http:// www.cverdad.org.pe/ifinal/ (30-12-2012).

Cornejo Polar, A. y L. F. Vidal, (comps.) (1984): Nuevo cuento peruano. Antología. Lima: Mosca Azul Editores.

Ezcárzaga, F. (2001): «Auge y caída de Sendero Luminoso». En: Bajo el volcán. Revista de posgrado de sociología. Segundo semestre, año/vol. 2, número 003. Puebla: Benemérita Universidad Autónoma de Puebla, 75- 97.

Flores Galindo, A. (2001): «La tradición autoritaria. Violencia y democracia en el Perú». En: Los rostros de la plebe. Barcelona: Crítica, 165- 194.

Gavilán Sánchez, L. (2012): Memorias de un soldado desconocido. Autobiografía y antropología de la violencia. Lima: Instituto de Estudios Peruanos.

Jiménez, E. (2009) [2005]: Chungui. Violencia y trazos de memoria. Lima: IEP, COMISEDH y DED-ZFD.

Roncagliolo, S. (2007): La cuarta espada. La bistoria de Abimael Guzmán y Sendero Luminoso. Buenos Aires: Debate.

Sarlo, Beatriz (2007): Tiempo pasado. Cultura de la memoria y giro subjetivo. Una discusión. Buenos Aires: Siglo XXI.

Sklodowska, E. (1992): Testimonio bispanoamericano. New York: Peter Lang.

Stern, S. (ed.) (1999): Los senderos insólitos del Perú. Lima: IEP-UNSCH.

Ubilluz, J. C., A. Hibbett y V. Vich (2009): Contra el sueño de los justos: la literatura peruana ante la violencia política. Lima: IEP.

Vargas Llosa, M. (2010) [1993]: Lituma en los Andes. Buenos Aires: Planeta.

Vich, V. (2015): Poéticas del duelo. Ensayos sobre arte, memoria y violencia política en el Perú. Lima: IEP. 
Betina Campuzano

National University of Salta

\section{Tattoos in the Memory: Autobiography and Violence in Contemporary Peru}

Keywords: subjectivity, testimony, autobiography, violence, Peru.

Over the past years, testimonial forms have become "icons of truth", that is to say, a resource to reconstruct recent memory (Sarlo, 2007). Contemporary to the so called linguistic twist, a subjective twist towards the use of the first person as the dominant form is taking place. Nowadays literary critics, historians, and ethnographers interested in popular culture are focusing on daily life. In other words, they study "normal" people who are the protagonists of transgressions and interchanges. Thus, rather than structures, what really matters is the subject, his identity and his reaffirmation.

We propose to analyze the Lurgio Galván Sánchez's Memories of an unknown soldier. Autobiograpby of violence (2012), which is the story of a Quechua speaking peasant who attended or participated in the country's dominant institutions, such as, the guerrilla, the army, the church, and the university, during the outburst of violence occurred in Peru in the course of the ' 80 s and ' 90 . We will examine, using discourse, how these institutions struggled to impose a hegemonic account on past events and also to identify the mechanisms these institutions devised in order to prolong the violence from the time of the colonial conquest. Since then, many subjectivities and stereotypes have been created, giving rise to exclusions and aggressions, which have been cyclically imprinting indelible tattoos on the national body right up to the present day. 
Betina Campuzano

Državna univerza $v$ Salti

\section{Vtetovirano v spomin: avtobiografija in nasilje $v$ Peruju v zadnjih letih}

Ključne besede: subjektivnost, spomin, avtobiografija, nasilje, Peru

V zadnjem času so pričevanjske oblike v književnosti postale »ikona resnice« oziroma način rekonstrukcije nedavnega spomina (Sarlo, 2007). Hkrati z jezikovnim izrazom smo priča očitnemu subjektivnemu izrazu pri rabi prve osebe, ki je dobila prednost. Literarni kritiki, zgodovinarji in etnologi, ki jih zanima popularna kultura, se osredotočajo na vsakdanjost in na »normalne« posameznike, ki kot protagonisti poosebljajo družbene odklone in izmenjave. Že dolgo jih ne zanimajo strukture, pomembni so posameznik, njegova identiteta in potrjevanje.

Predstaviti želimo delo Memorias de un soldado desconocido. Autobiografía y antropología de la violencia (2012) avtorja Lurgia Gavilána Sáncheza. Gre za zgodbo o kmetu, govorcu kečue, ki je imel v obdobju najhujšega nasilja v 8o. in 90. letih v Peruju opravka z najpomembnejšimi institucijami (gverilo, vojsko, cerkvijo in univerzo). Na podlagi analize diskurza bomo preizprašali načine, na katere so te institucije vzpostavile hegemonični diskurz o preteklih dogodkih in kateri vzvodi omogočajo kontinuirano nasilje vse od časov konkviste. Odtlej so se izgradile subjektivnosti in stereotipi, temeljijo pa na izključevanju in agresiji, ki se ciklično ponavljata in tako narodu neizbrisno vtetovirata $\mathrm{v}$ zavest podobe, ki obstajajo še danes. 